\title{
The elimination of meat from the diet selectively decreases pancreatic elastase secretion
}

\author{
Jaroslaw Walkowiak ${ }^{1 *}$, Lidia Wadolowska ${ }^{2}$, Anna Szaflarska-Poplawska ${ }^{3}$, Aleksandra Lisowska ${ }^{1}$, \\ Alina Bugajewska ${ }^{1}$ and Juliusz Przyslawski ${ }^{4}$ \\ ${ }^{1}$ Department of Gastroenterology \& Metabolism, Poznan University of Medical Sciences, Poznan, Poland \\ ${ }^{2}$ Institute of Human Nutrition, University of Warmia and Mazury, Olsztyn, Poland \\ ${ }^{3}$ Collegium Medicum, Mikolaj Kopernik University, Torun, Poland \\ ${ }^{4}$ Department of Human Nutrition, Poznan University of Medical Sciences, Poznan, Poland
}

(Received 6 June 2006 - Revised 4 December 2006 - Accepted 10 January 2007)

\begin{abstract}
Since the vegetarian diet lacks the substrate for pancreatic elastase- 1 as an enzyme, a decreased secretion of this enzyme could be expected. We aimed therefore to assess the changes of exocrine pancreatic secretion in a prospective way in a group of healthy omnivores who modified their diet by abstaining from meat for 1 month. Twenty healthy omnivores (fourteen females and six males) were used in the study. The nutrient intake was assessed for $7 \mathrm{~d}$ before commencing the study (omnivore diet) and after 1 month of dietary modification (modified diet; meat excluded). Similarly, the faecal output of pancreatic enzymes (elastase-1, chymotrypsin and lipase) was assessed before and 1 month after the period of dietary modification. Statistical differences between two points of the assessment (paired data) were calculated with the use of the Wilcoxon rank test. The relationship between the changes of faecal enzyme output and the changes in nutrient intake was assessed using multiple regression analysis. The dietary changes resulted in statistically significant decrease of faecal elastase- 1 output $(P<0 \cdot 05)$, whereas for chymotrypsin and lipase no changes were observed. No significant change in stool weight was recorded. No statistically significant correlation between changes in energy and nutrient consumption and changes in faecal output of pancreatic enzymes has been found. It was concluded that the exclusion of meat from the diet for a 1-month period results in significant changes in pancreatic secretion with a selective decrease of elastase-1 output. However, the underlying factor remains unclear.
\end{abstract}

Exocrine pancreatic secretion: Faecal enzymes: Nutrition: Meat: Lactoovovegetarian diet

The effect of a vegetarian diet on exocrine pancreatic secretion creates an interesting opportunity for the assessment of pancreatic adaptation to human nutrition. In a group of twenty lactoovovegetarians pancreatic exocrine secretion was assessed and compared to that of thirty-two non-vegetarian subjects (Walkowiak et al. 2006). Daily faecal elastase-1 (FE1) and chymotrypsin (FCht) outputs in vegetarians and omnivores did not differ significantly. Since a vegetarian diet lacks the substrate for pancreatic elastase-1 as an enzyme, a decreased secretion of this enzyme could be expected. However, such a phenomenon was not reported in the study (Walkowiak et al. 2006). Neither was any correlation between nutrient intake and pancreatic enzyme secretion stated. The limitation of the study was related to a cross-sectional model of the assessment (non-paired data). The significant differences in the intake of several nutrients between lactoovovegetarians and non-vegetarian subjects could also influence the results.

The vegetarian diet is becoming increasingly popular, yet there is no information on adaptation of pancreatic secretion to this dietary modification. Therefore, its potential influence should be elucidated. In the present study we aimed to assess the changes of exocrine pancreatic secretion in a prospective way in a group of healthy omnivores who modified the diet by abstaining from meat for 1 month.

\section{Materials and methods}

Study design

The study lasted for 5 weeks. Healthy omnivore volunteers abstained from all products containing meat and replaced them with lactoovovegetarian products for the period of the study. The nutrient intake was assessed for $7 \mathrm{~d}$ before entering the study (omnivore diet) and after 1 month of dietary modification (modified diet; meat excluded). Similarly, the faecal output of pancreatic enzymes (FE1, FCht and faecal lipase (FLP)) was assessed before and 1 month after the period of dietary modification. Inclusion criteria were being an omnivore, having good general and nutritional status, and a willingness to participate in the study. Exclusion criteria were any history of gastrointestinal or systemic disease, any acute

\footnotetext{
Abbreviations: FE1, faecal elastase-1; FCht, faecal chymotrypsin; FLP, faecal lipase.

* Corresponding author: Professor Jaroslaw Walkowiak, fax 4861 8483362, email jarwalk@am.poznan.pl
} 
disease within 1 month prior to or during the study, and discontinuation of dietary modification during the study.

The sample size was established according to Altman's normogram (Petrie \& Sabin, 2005). There were no drop-outs during the study. The volunteers were selected from students and young workers of the University of Warmia and Mazury. Exclusively highly motivated and enthusiastic subjects were entered in the study. Volunteers received detailed information on meat-containing and meat-free products, as well as several examples of different meals. The diet compliance was checked three times per week.

\section{Subjects}

Twenty healthy omnivores (fourteen females and six males) aged 22 to 26 years (mean age 24.1(SD 0.8) years) were included into the study. Their BMI values were in the range of 18.0 to $29.3 \mathrm{~kg} / \mathrm{m}^{2}$ (mean 21.6 (SD 2.9$) \mathrm{kg} / \mathrm{m}^{2}$ ).

\section{Methods}

The assessment of nutrient intake (all available macro- and micronutrients) was based on the records of 7-d weighed rations. The records (with use of scales with an approximation of $0 \cdot 1 \mathrm{~g}$ ) were collected at home. Subjects were given both oral and written instructions. The diet records were reviewed and clarified (JP). The obtained data were analysed using our own, previously created, computer database (Microsoft Access 7.0; J.P.) prepared on the basis of tables for the composition and nutritional value of food products (Kunachowicz et al. 2005). The degree to which the recommended intake was met was considered in relation to values given by the National Institute of Food and Nutrition in Warsaw (Ziemlański et al. 1994). Physical activity was assessed by a 7-d recall (Ziemlański \& Bułak-Jachymczyk, 2001). All subjects were found to have moderate activity which did not differ between the two periods of the study.

Faecal enzymes were determined in three independent samples of every stool. For further analysis the mean value was taken. FE1 concentration (the test based on monoclonal antibodies) and FLP activity were measured by use of an immunoenzymatic method (ELISA) (Scheefers-Borchel et al. 1992, Walkowiak et al. 2004a), whereas FChT activity was measured using a colorimetric method (Brown et al. 1988). Faecal enzyme output was calculated according to the following formula:

$$
\mathrm{FEO}=\frac{\mathrm{FE}_{1} \times \mathrm{SW}_{1}+\cdots+\mathrm{FE}_{n} \times \mathrm{SW}_{n}}{3}
$$

where FEO is faecal enzyme output, $\mathrm{FE}_{\mathrm{n}}$ is faecal enzyme concentration/activity in subsequent $(n)$ stool and $\mathrm{SW}_{n}$ is stool weight of subsequent $(n)$ stool.

The protocol of the investigation was approved by the Ethical Committee of the Poznan University of Medical Sciences, Poland.

\section{Statistical analysis}

Statistical differences in nutrient intake, stool weight and faecal enzyme output between two points of the assessment (paired data) were calculated with the use of the Wilcoxon rank test. The relationship between the changes of faecal enzyme output and the changes in nutrient intake (all available macro- and micronutrients) was assessed using multiple regression analysis.

If not stated otherwise, values are expressed as means with their standard deviation. The level of significance was set at $P<0.05$.

\section{Results}

The daily output of FE1, FCht and FLP on an omnivore diet and on the modified diet are given in Table 1. Dietary changes resulted in a statistically significant decrease of FE1 output $(P<0.05)$, whereas for FCht and FLP no changes were observed. In addition, no significant changes in stool weight were recorded (100.9 (SD 53.1) v. 102.2 (SD 63.4) g/day).

The comprehensive nutritional data are presented in Table 2. No significant changes in the consumption of energy, total protein, fibre or SFA were found. However, a significant increase of plant protein $(P<0.003)$ and carbohydrate $(P<0.02)$ intake and the decrease of animal protein $(P<0.006)$, fat $(P<0.006)$, Se $(P<0.003)$, MUFA $(P<0.01)$ and PUFA $(P<0.02)$ were found.

No statistically significant correlation between relative and non-relative changes in energy and nutrient consumption and changes in faecal output of pancreatic enzymes was found.

\section{Discussion}

Pancreatic adaptation occurs in response to different dietary nutrients. The assessment of the effect of a vegetarian diet on exocrine pancreatic secretion therefore creates an interesting opportunity for the evaluation of this adaptive process. Faecal tests are the most sensitive and specific indirect tests for the assessment of pancreatic function and secretion (Walkowiak et al. 2005). As reported for healthy subjects (Stein et al. 1996) and patients with severe exocrine pancreatic deficiency (Walkowiak et al. 1999), FE1 concentrations correlate significantly with parameters of direct tests that are the gold standard in the assessment of pancreatic function. Also, the vegetarian diet lacks the substrate for pancreatic elastase- 1 as an enzyme and decreased secretion of elastase- 1 in vegetarians could be expected (Walkowiak et al. 2004b). Therefore, we used an FE1 test for the assessment of changes in exocrine pancreatic secretion. On the other hand, a vegetarian diet potentially gives the stimulation for chymotrypsin secretion. Therefore

Table 1. Daily faecal elastase-1 (FE1), chymotrypsin (FCht) and lipase (FLP) output on omnivore (OV) and on modified (MD) diet

\begin{tabular}{|c|c|c|c|c|}
\hline \multirow[b]{3}{*}{ Output } & \multicolumn{4}{|c|}{ Period } \\
\hline & \multicolumn{2}{|r|}{ OV } & \multicolumn{2}{|r|}{$M D$} \\
\hline & Median & $\begin{array}{l}\text { 1st }-3 r d \\
\text { quartile }\end{array}$ & Median & $\begin{array}{l}\text { 1st }-3 r d \\
\text { quartile }\end{array}$ \\
\hline FE1 $(\mu \mathrm{g} / \mathrm{d})$ & 60323 & $36224-85600$ & 41205 & $26120-66400$ \\
\hline FCht (U/d) & 1854 & $1479-3124$ & 1397 & $1176-2708$ \\
\hline FLP (U/d) & 7946 & $4175-20300$ & 7074 & $3739-19333$ \\
\hline
\end{tabular}


Table 2. Changes of energy and nutrient intake resulting from the change of diet (omnivore $v$. modified diet)

\begin{tabular}{|c|c|c|c|c|c|c|c|c|c|c|}
\hline \multirow[b]{2}{*}{ Nutrient } & \multicolumn{3}{|c|}{ Omnivore diet } & \multicolumn{3}{|c|}{ Modified diet } & \multicolumn{3}{|c|}{ Relative changes* } & \multirow[b]{2}{*}{$P$} \\
\hline & Median & Mean & 1st - 3rd quartile & Median & Mean & 1st - 3rd quartile & Mean & SD & Median & \\
\hline Energy (kcal) & 2212 & 2142 & $1729-2465$ & 2083 & 2167 & $1712-2669$ & $101 \cdot 8$ & $22 \cdot 3$ & $95 \cdot 0$ & NS \\
\hline Protein (g) & $69 \cdot 0$ & $72 \cdot 2$ & $60 \cdot 1-79 \cdot 7$ & $61 \cdot 8$ & 65.9 & $50 \cdot 9-82 \cdot 2$ & 93.5 & $26 \cdot 3$ & $90 \cdot 1$ & NS \\
\hline Animal protein (g) & $46 \cdot 0$ & 47.4 & $38 \cdot 0-56 \cdot 9$ & 31.9 & 34.5 & $26 \cdot 9-40 \cdot 9$ & $78 \cdot 3$ & 34.6 & 65.4 & 0.006 \\
\hline Plant protein $(\mathrm{g})$ & 23.9 & 24.8 & $18 \cdot 8-26 \cdot 9$ & $26 \cdot 5$ & 31.3 & $24 \cdot 6-40 \cdot 4$ & $129 \cdot 0$ & $32 \cdot 8$ & $125 \cdot 3$ & 0.003 \\
\hline Carbohydrates (g) & $252 \cdot 7$ & $261 \cdot 3$ & $193 \cdot 5-329 \cdot 4$ & 303.7 & $315 \cdot 4$ & $246.4-373 \cdot 8$ & $123 \cdot 14$ & $31 \cdot 0$ & $124 \cdot 1$ & 0.02 \\
\hline Fat $(\mathrm{g})$ & $89 \cdot 7$ & $92 \cdot 3$ & $78 \cdot 2-109 \cdot 5$ & $77 \cdot 8$ & $75 \cdot 8$ & $59 \cdot 1-85.9$ & 83.4 & $20 \cdot 0$ & $82 \cdot 6$ & 0.006 \\
\hline SFA (g) & 30.6 & $32 \cdot 2$ & $25.5-38.9$ & $28 \cdot 7$ & $30 \cdot 0$ & $24 \cdot 7-33 \cdot 8$ & $94 \cdot 1$ & $22 \cdot 3$ & $92 \cdot 8$ & NS \\
\hline MUFA $(\mathrm{g})$ & 36.5 & $35 \cdot 0$ & $29 \cdot 0-40 \cdot 8$ & 24.9 & $25 \cdot 9$ & $20.5-31.0$ & 77.4 & 24.5 & $76 \cdot 1$ & 0.01 \\
\hline PUFA (g) & 13.7 & $14 \cdot 2$ & $11 \cdot 2-17 \cdot 8$ & $10 \cdot 4$ & $10 \cdot 9$ & $8 \cdot 6-12 \cdot 3$ & $81 \cdot 3$ & $31 \cdot 2$ & $77 \cdot 8$ & 0.02 \\
\hline Fibre (g) & $19 \cdot 1$ & $19 \cdot 0$ & $15 \cdot 5-22 \cdot 7$ & $19 \cdot 6$ & $21 \cdot 8$ & $16 \cdot 8-27 \cdot 5$ & $116 \cdot 6$ & 34.5 & 111.3 & NS \\
\hline $\mathrm{Se}(\mu \mathrm{g})$ & 358 & 452 & $300-554$ & 310 & 305 & $203-353$ & $75 \cdot 3$ & 33.1 & $59 \cdot 0$ & 0.003 \\
\hline
\end{tabular}

${ }^{*}$ Value expressed as a percentage of original value (\%).

the measurement of FCht activity served as a control parameter.

Exocrine pancreatic secretion could be assessed in different ways. In short-term dietary modification the steady collection of pancreatic juice could be applied (Boivin et al. 1990). However, it limits the period of observation. The effects of longterm dietary changes could be assessed by the repeated performance of direct pancreatic function tests (Zoppi et al. 1972). The maximal hormonal stimulation may not reflect the real interdigestive and postprandial changes in pancreatic secretion due to dietary stimulation. The disadvantage of both methods is related to their being invasive. In the present study, we assessed faecal output of pancreatic enzymes. Parallel assessment of dietary intake and pancreatic secretion as well as physiological way of pancreatic stimulation (diet) is the advantage of such an attitude. Considering the limitation of indirect pancreatic function tests we assessed daily faecal output for $3 \mathrm{~d}$ instead of concentration/activity in a single stool sample. Since FE1 concentrations in healthy subjects correlate significantly with the parameters of direct test (Stein et al. 1996), the observed decrease of elastase-1 secretion seems to be highly reliable.

In the present study, we assessed the changes of exocrine pancreatic secretion in a group of healthy omnivores who modified the diet by abstaining from meat for 1 month. In contrary to the previously assessed cross-sectional model comprising vegetarian and omnivore subjects (Walkowiak et al. 2006), the use of a prospective model revealed the selective adaptation of pancreatic secretion. The dietary changes resulted in a statistically significant decrease of pancreatic secretion as measured by FE1 output. On the other hand, Fcht and FLP excretions remained unchanged. Since the vegetarian diet is becoming increasingly popular this information is of potential significance.

The ability of the pancreas to adapt to changes in dietary intake was initially noted by Pavlov. Subsequent animal studies clearly demonstrated that proteolytic, amylolytic and lipolytic synthesis changes proportionately in response to the amount of their respective dietary substrates: proteins, carbohydrates and fat (Pitchumoni \& Scheele, 1993). The data available for human subjects are sparse. Zoppi et al. (1972) reported that in premature infants a starch-enriched diet stimulated amylase secretion, whereas a high-protein diet led to the increase of trypsin and lipase levels. The increase of fat intake did not result in any changes. In another study of premature infants (Lebenthal et al. 1981), a significant increase of secretin- and cholecystokinin-stimulated trypsin and lipase output in a subgroup fed soya-based formula containing increased protein was reported. In adult volunteers, low-fat and high-carbohydrate diets resulted in a higher output of trypsin and chymotrypsin as measured by a secretin-cholecystokinin test (Emde et al. 1985). In contrast to animal models, no adaptation of amylase and lipase secretion was found. Boivin et al. (1990) concluded in their study that diets containing a high proportion of calories as carbohydrate are associated with lower interdigestive and postprandial pancreatic secretion than diets with a high fat content. Keefe (2006) reported that changing the formula of the diet from polymeric to elemental in duodenally fed subjects resulted in a $50 \%$ decrease in pancreatic secretion. This can be explained both by the elemental nature of the diet and by the fact that the elemental formula has a low fat content and fat is one of the major stimulatory effects on cholecystokinin release (Owyang et al. 1986). This agrees with findings reported by Keller et al. (1997).

The changes in the intake of major dietary nutrients observed in the present study are minor in comparison to those in the studies described earlier. However, the qualitative changes in fat (MUFA and PUFA) and protein profile (animal and plant sources) were observed. According to the suggested feedback mechanism in the control of pancreatic secretion, the changes in the intake of protein could modify pancreatic protease output (Owyang et al. 1986). Animal and plant proteins have different structure (Gawecki, 1997) and may potentially cause different pancreatic secretion. However, there are no data available concerning this subject in vegetarians. There is also evidence that the Mediterranean diet with higher MUFA consumption decreases pancreatic secretion (Alarcon de la Lastra et al. 2001). The intake of MUFA was statistically lower during the modified diet than during the omnivore period of the study, which could hypothetically favour pancreatic secretion in vegetarians. On the other hand, PUFA consumption was significantly lower during the 1-month period of modified diet. The major dietary PUFA (linoleic, linolenic and arachidonic acids) were reported to stimulate in vitro pancreatic secretion (Egberts et al. 2000). Therefore, the decrease of pancreatic secretion could be expected. 
Other factors possibly influencing pancreatic secretion in vegetarians are higher consumption of soya-bean trypsin inhibitors (Folsch \& Creutzfeldt, 1985; Holm et al. 1992) and dietary fibre (Isaksson et al. 1982; Dutta \& Hlasko, 1985) and lower intake of Se (Jackson et al. 2003). However, soya is commonly added to products commercially available for omnivores. In addition, a soya-containing diet (due to the different analytical methods) could result in a decrease of FCht activity and would possibly result in an increased FE1 concentration (Walkowiak \& Herzig, 2004). Furthermore, dietary fibre has been shown to affect pancreatic enzyme activity in vivo and in vitro (Isaksson et al. 1982; Dutta \& Hlasko, 1985). Therefore, enzyme activity could be decreased (e.g. for chymotrypsin). However, the immunoenzymatic method determines FE1 concentrations and not activity. Finally, Se intake in vegetarians was reported to be lower than in omnivores (Larsson \& Johansson, 2002). Possible involvement of selenoproteins in the human pancreatic secretory process has been suggested (Weizman, 2004) and cannot be excluded, but has not been reported. However, the functional consequence of decreased Se intake is unclear (Jackson et al. 2003).

Since no significant correlation between relative and nonrelative changes of energy and nutrient consumption and pancreatic secretion was found, we could assume that the observed quantitative and qualitative changes played a minor role. The major hypothetical dietetic influence was in fact related to the exclusion of meat from the diet. The lack of the substrate (meat) for the enzyme (elastase-1) might be responsible for the observed selective changes in pancreatic enzyme secretion. The consumption of MUFA and PUFA decreased significantly, being the 'adverse effect' of the diet. The increased consumption of dairy products was the underlying factor. This bystander effect underlines the significance of a thorough dietary consideration in vegetarians. However, subjects included in the study were not regular vegetarians. They volunteered for a 1-month period. Therefore, their diet could not represent a genuine lactoovovegetarian diet. It could be also the underlying cause of the lack of changes in stool weight. Therefore, we can only comment on the influence of the exclusion of meat from the diet rather than on a genuine lactoovovegetarian diet.

In conclusion, the exclusion of meat from the diet for a 1 -month period resulted in significant changes in pancreatic secretion with a selective decrease of elastase-1 output. However, the underlying factor remains unclear.

\section{Acknowledgement}

This investigation was supported in part by the Polish Scientific Research Committee (3 P05D 033 22).

\section{References}

Alarcon de la Lastra C, Barranco MD, Motilva V, et al. (2001) Mediterranean diet and health: biological importance of olive oil. Curr Pharm Des 7, 933-950.

Boivin M, Lanspa SJ, Zinsmeiser AR, et al. (1990) Are diets associated with different rates of human interdigestive and postprandial pancreatic enzyme secretion? Gastroenterology 99, 1763-1771.
Brown GA, Sule D, Williams J, et al. (1988) Faecal chymotrypsin: a reliable index of exocrine pancreatic function. Arch Dis Child 63, $185-189$.

Dutta SK \& Hlasko J (1985) Dietary fiber in pancreatic disease: Effect of high fiber diet on fat malabsorption in pancreatic insufficiency and in vitro study of the interaction of dietary fiber with pancreatic enzymes. Am J Clin Nutr 41, 517-525.

Egberts J, Brunke G, Kiehne K, et al. (2000) CCK release by longchain unsaturated fatty acids from isolated perfused mucosal cells. Gastroenterology 118, A301.

Emde C, Liehr R-M, Gregor M, et al. (1985) Lack of adaptive changes in human pancreatic amylase and lipase secretion in response to high-carbohydrate, low-fat diet applied by a 10-day continuous intraduodenal infusion. Dig Dis Sci 30, 204-210.

Folsch UR \& Creutzfeldt W (1985) Adaptation of the pancreas during treatment with enzyme inhibitors in rats and man. Scand J Gastroenterol 112, Suppl., 4-63.

Gawecki J (1997) Proteins in food and nutrition, pp. 1-107 (in Polish). Poznan, Poland: August Cieszkowski Agricultural University.

Holm H, Reseland JE, Thorsen LI, et al. (1992) Raw soybeans stimulate human pancreatic proteinase secretion. $J$ Nutr 122, $1407-1416$.

Isaksson G, Lundquist I \& Ihse I (1982) Effect of dietary fiber on pancreatic enzyme activity in vitro. Gastroenterology 82, 918-924.

Jackson MJ, Broome CS \& McArdle F (2003) Marginal dietary selenium intakes in the UK: are there functional consequences? J Nutr 133, Suppl. 1, 1557S-1559S.

Keefe SJD (2006) Physiological response of the human pancreas to enteral and parenteral feeding. Curr Opin Clin Nutr Metab Care 9, 622-628.

Keller J, Ruzzi M, Goebell H \& Layer P (1997) Duodenal and ileal nutrient deliveries regulate human intestinal motor and pancreatic response to a meal. Am J Physiol Gastrointest Lver Physiol 272, G632-G637.

Kunachowicz H, Nadolna I, Przygoda B, et al. (2005) Nutritional value of food products, pp. 1-671 (in Polish). Warsaw: Instytut Żywności i Zywienia.

Larsson CL \& Johansson GK (2002) Dietary intake and nutritional status of young vegans and omnivores in Sweden. Am J Clin Nutr 76, 100-106.

Lebenthal E, Choi TS \& Lee PC (1981) The development of pancreatic function in premature infants after milk-based and soy-based formulas. Pediatr Res 15, 1240-1244.

Owyang C, Louie DS \& Tatum D (1986) Feedback regulation of pancreatic enzyme secretion: suppression of cholecystokinin release by trypsin. J Clin Invest 77, 2042-2047.

Petrie A \& Sabin C (2005) Sample size calculations. In Medical Statistics at a Glance, pp. 84-86. Oxford: Blackwell Publishing Ltd.

Pitchumoni CS \& Scheele GA (1993) Interdependence of nutrition and exocrine pancreatic function. In The Pancreas: Biology, Pathobiology, and Disease, pp. 449-473 [V Liang W Go, et al. editors]. New York: Raven Press Ltd.

Scheefers-Borchel U, Scheefers H, Arnold R, et al. (1992) Pancreatic fecal elastase-1: parameter for chronic and acute pancreatitis. Lab Med 16, 427-434.

Stein J, Jung M, Sziegoleit A, et al. (1996) Immunoreactive elastase 1: clinical evaluation of a new noninvasive test of pancreatic function. Clin Chem 42, 222-226.

Walkowiak J, Cichy WK \& Herzig KH (1999) Comparison of fecal elastase-1 determination with secretin-cholecystokinin test in patients with cystic fibrosis. Scand J Gastroenterol 34, 202-207.

Walkowiak J \& Herzig KH (2004) Vegetarian diet and exocrine pancreatic function using fecal tests: The authors' reply. J Pediatr Gastroenterol Nutr 39, 212-213.

Walkowiak J, Lisowska A, Przyslawski J, et al. (2004a) Faecal elastase test is superior to faecal lipase test in the assessment of 
exocrine pancreatic function in cystic fibrosis. Acta Paediatr 93, $1042-1045$.

Walkowiak J, Nousia-Arvanitakis S, Henker J, et al. (2005) The use of indirect pancreatic function tests in children. J Pediatr Gastroenterol Nutr 40, 107-114.

Walkowiak J, Songin A, Przyslawski J, et al. (2004b) Vegetarian diet alters the assessment of exocrine pancreatic function with the use of fecal tests. J Pediatr Gastroenterol Nutr 38, 224-226.

Walkowiak J, Songin A, Przyslawski J, et al. (2006) Exocrine pancreatic secretion and nutrient intake in lactoovovegetarians. In Proceedings of Pediatric Gastroenterology, pp. 268-275 [M Korzon, B Kaminska, A Szarszewski, editors]. Torun: WAM.
Weizman Z (2004) Vegetarian diet and exocrine pancreatic function using fecal tests. J Pediatr Gastroenterol Nutr 39, 212.

Ziemlański S, Bułak-Jachymczyk B \& Budzynska-Topolowska J (1994) Recommended nutrient intake for Polish population (energy, protein, fat, vitamins, macro- and micronutrients). $\dot{Z} y w$ Czkow Metabol 21, 303-338 (in Polish).

Ziemlański S \& Bułak-Jachymczyk B (2001) Energy needs in humans. In: Normal values in human nutrition. Physiological basis, pp. 35-57 [S Ziemlański, editor] (in Polish). Warsaw: PZWL.

Zoppi G, Andreotti G, Pajno-Ferrara F, et al. (1972) Exocrine pancreas function in premature and full term neonates. Pediatr Res 6, 880-886. 